\title{
Un capitulo en la historia de la moral matrimonial
}

A propósito del "Adversus Jovinianum" de S. Jerónimo y del "De Bono Coniugali” de S. Agustín.

Se ha convertido ya en un tópico en los estudios históricos sobre las doctrinas de cualquier rama del saber, el encontrarse con un conjunto de dificultades anejas a toda obra de relaciones, una vez acercados al análisis de los diversos autores. Por una parte, la dificultad mayor sería el dejarnos llevar de ciertos presupuestos, aplicando nuestras categorias de pensamiento a una cierta época en que no nos tocó vivir y de la cual, aunque conozcamos con mayor o menor precisión la idiosincrasia y la dirección del pensamiento, no obstante, siempre nos será difícil el formarnos un juicio crítico justo sobre el argumento que nos preocupará.

Por otra, la gran dificultad en conocer a los autores, su psicología, su formación humana e intelectual a la vez que religiosa, que siempre, queramos o no, dejará una impronta más o menos profunda en sus obras.

Con el fin de salvar estos escollos en la medida de nuestras posibilidades y en cuanto nos es necesario para tal estudio, hemos creído oportuno el delimitar posiciones y conjugar datos, en torno a las relaciones más o menos íntimas y ciertas de ambos autores. Es un hecho, que quedará probado a través de estas líneas, que los dos han dirigido sus obras contra Joviniano. De aquí que no podamos por menos que comenzar por una primera parte sobre la cuestión histórica, como de un trampolín del cual nos podemos lanzar a profundizar y a comprender el alcance de la función desarrollada por la obra de Agustín en relación con la de Jerónimo. En esta parte careceremos muchas veces de datos históricos que demues- 
tren la realidad de nuestras afirmaciones. Caminaremos, con frecuencia, en hipótesis y nos será difícil el entrar en la entraña misma de la relación, Jerónimo-Agustín.

\section{A.- PRESUPUESTOS HISTORICOS:}

\section{Relaciones entre Jerónimo y Agustin:}

Una pregunta nos sale rápidamente al paso cuando queremos intentar poner de manifiesto la relación Jerónimo-Agustín. $Y$ es el motivo, el lugar y el cuándo Agustín llegó al conocimiento de Jerónimo. Podemos partir inicialmente con fundamentos históricos. Sabemos que el año 383 Jerónimo se halla en Roma como secretario del Papa Dámaso. Por este año un joven africano se acerca por Roma en busca de fortuna ${ }^{1}$. No existe noticia alguna de su encuentro y el sentir común opina que ni siquiera sospechasen uno de otro, cosa por otra parte no muy difícil en aquel ambiente romano cosmopolita y sin que representasen personalidad todavia.

Agustín se dirige a Milán ${ }^{2}$, mientras que Jerónimo parte para Palestina ${ }^{3}$. Al africano lo encontramos con ciertas inquietudes por entrar en la Iglesia católica. Un retórico de la talla de Agustín necesitaba fuertes convicciones y ejemplos. S. Ambrosio es fácil que le hablase de un tal Jerónimo que de la noche a la mañana deja todo y se retira al desierto. Nos hallamos en el tiempo de la conversión de Agustín al monaquismo. Se siguen las escenas en el huerto de Milán, y ante la narración de diversos personajes que se han ido al yermo, encontramos en las Confesiones dos que nos van a preocupar". Simplemente se nos habla de dos "agentes in rebus". Aquí los autores comienzan a divagar y a encontrar sus nombres y en concreto es Courcelle quien precisa sus nombres. Pierre Courcelle, después de exponer unos cuantos datos en torno a este suceso, termina haciéndose la pregunta: "N'est pas un motif sérieux de supposer que Jerôme et Bonose sont les deux fonctionaires donc parle Pontititianus "convertis" pour avoir découvert a Tréves la Vie d'Antoine? .

1. S. Agustín, Confesiones (Trad de A. C. VEGA), (Madrid 1946), nota del libro V, p. 507

2. Confess., $\mathrm{V}, 13,23$ PL 32,717 .

3. F. Cavallera, Saint Jerôme, sa vie et son oeuvre. (Paris-Louvain 1922) II, 22.

4. Confess. VIII, 6,15 PL 32,750. 
La suposición del autor no parece infundada si consideramos bien las circunstancias en que se movía todo esto. Sin duda, Ponticiano diera sus nombres, pero Agustín por circunstancias que no conocemos, al llegar a este punto de su obra, hace punto blanco.

El año 387 de nuevo Agustín pasa por Roma en dirección a Africa. Un año de estancia en la Urbe le sirve para tomar noticias acerca del monacato, que más tarde le serviría de ayuda. Ya por este tiempo, Jerónimo había dejado en Roma la estela de sus ideas en torno a la vida ascética y monacal. Agustín se enteró aquí de las instituciones inspiradas más o menos por las ideas jeronimianas. Incluso algunos de los escritos del Santo llegaron a su mente como fácilmente podemos colegir de la terminología usada en sus escritos sobre el monacato, algunos de los cuales muestran una influencia marcadamente jeronimiana. Tomaría relaciones también con Pammaquio, íntimo de Jerónimo a quien le escribirá después ${ }^{6}$.

\section{Epistolario mutuo. La incógnita del viaje de Alipio a Palestina}

Punto central y seguro de partida ante el cual podemos detenernos y comenzar con datos precisos sobre las relaciones entre ambos santos, es, sin duda, las relaciones literarias entre los dos. Alipio se dirige a Palestina. No sabemos, y los autores se callan, ni la causa del viaje ,ni el tiempo, año seguro, ni cuándo volvió. Sabemos de su viaje y de la entrevista con Jerónimo ${ }^{7}$ y que recogió noticias y libros para traérselos a Agustín. Hasta tal extremo llegó la simpatía de Jerónimo con Alipio que nunca se olvidará de él en las cartas que dirige a Agustín ${ }^{8}$.

Alipio, podemos concluir, fue el medio directo y seguro por el cual Agustín conoce a Jerónimo. El mismo Agustín nos lo conflesa en su primera carta a Jerónimo ${ }^{\circ}$. Jerónimo de la misma manera se expresa diciendo que oyó hablar de él por medio de Alipio ${ }^{10}$.

5. P. CoURCELLE, Recherches sur les Confessions de saint Augustin. (Paris 1950), 185.

6. Aug: Exist. ad Pammachium, 58 PL 33,225 .

7. HIr. Epist. 103,2 PL 22,831; 115 PL 22,235; 142 PL 22,1180; 143 PL 22,$1181 ; 28,1$ PL 33,111 .

8. Hrr. Epist. 103,2 PL 22,831.

9. Aug. Epist 28,1 PL 33,111.

10. HIER. Epist. 105,2 PL 22,835. 
Agustín ve en Jerónimo una ayuda en las circunstancias duras de este tiempo en lucha contra las herejías que día a día se veían surgir florecientes y a las cuales debia afrontar consciente de su deber de pastor de almas. Podemos colegir que la ida de Alipio a Palestina estuviera ocasionada por todo esto. No excluimos el hecho de que posiblemente fuera en busca de códices y demás, pero no olvidemos que Agustín se había formado una idea del monacato y para llevarla a su realización necesitaba datos de experiencia y de ningún lugar le podian venir mejor, que de Palestina donde las comunidades de monjes se multiplicaban.

Schmid cree ver en el hecho de haber recibido Agustín algún libro de Jerónimo, el primer chispazo que hace saltar la llama en esta correspondencia tan paradojica entre Jerónimo y Agustín " Agustín en la primera carta dirigida a Jerónimo manda como portador de la misma a Profuturo ${ }^{12}$. Juntamente con la carta manda algunos de sus escritos para que se digne corregirlos ${ }^{13}$. Ya antes Agustín había recibido por medio de Alipio parte de los de Jerónimo ${ }^{14}$. La carta parece ser que no llegó a manos de Jerónimo. Profuturo muere en el camino antes de llegar ${ }^{15}$. Algunos creen que fue escrita hacia el $391^{16}$, mientras que otros la ponen entre el 394-395.

A Agustín lo vemos inquieto por la ausencia de noticias de parte de Jerónimo y de nuevo le manda un billete de felicitación. Jerónimo responde a Agustín, pero la carta no llega. Este, de nuevo escribe otra explicándole la cuestión de la anterior ${ }^{17}$. En ella pone los argumentos esenciales sobre los que se desenvuelve esta correspondencia. La cuestión Antioquena ocupa el lugar central, amén de otros puntos. La carta cambia de rumbo y va a parar a Roma siendo leída por todos. Cinco años después la recibe Jerónimo de manos de Sysinnio ${ }^{18}$ enterándose de lo sucedido con ella anteriormente. La lee y dado el contenido de la misma no le viene muy de su agrado el que haya pasado por manos ajenas. Este he-

11. J. Schmid, Florilegium Patristicum, Fasciculus XXII, SS. Eusebii, Hieronymi et Aurelii Augustini Epistulae mutuae. (Bonn 1930) 11.

12. AUG. Epist. 28,1 PL 33,111.

13. Aug. Epist. 28,5 PL 33, 113-114.

14. AUG. E'pist. 28,3 PL $33,113$.

15. HIER. Epist. 104,2 PL 22,832; 105,1 PL 22,835.

16.. G. Sigmard, "La querelle de deux saints. Saint Jerôme et saint Augustin": Revue de l'Université d'Ottawa 12(1942) 18.

17. AuG. Epist. 40,1 PL 33,154.

18. HIER. Epist. 105,1 PL 22,835. 
cho será una cuestión candente a través de todo el epistolario restante.

En la mente de Agustín cada día se van agrupando sospechas de un fracaso en el diálogo con Jerónimo; espera noticias y no llegan. El está seguro de que Jerónimo ya ha recibido la carta ${ }^{19}$. No obstante, la insistencia de Agustín cada día se hace más fuerte y le envia otra poniendo la disculpa de que quizás a Jerónimo, ocupaciones superiores a sus fuerzas no le permitan contestar ${ }^{20}$. Le habla de lo ocurrido en la carta anterior. Ella no va contra Jerónimo, simplemente se ciñe a dar una opinión particular. De parte de Agustín la cosa está clara, queda que Jerónimo lo comprenda ${ }^{21}$.

Finalmente Jerónimo se decide a escribir de nuevo a Agustín. La carta está escrita antes de llegar la última de Agustín ${ }^{22}$. Le habla sobre la que se hizo pública en Roma, pero no puede creer que sea copia la que ha recibido de la de Agustín. Sin embargo, se abstiene de responderle a lo que antes le habia preguntado. No obstante, las relaciones literarias no se cortan. Siguen comunicándose $^{23}$ y Jerónimo insistiendo en que le dé fe de que la carta que se hizo pública en Roma era suya, de lo contrario, tendrá que optar por cambiar de actitud ${ }^{24}$. Agustín era incapaz de no decir las cosas claras a Jerónimo y para que esté más seguro le manda uno de los suyos. Se nos revelan a las claras los dos en sus maneras de reaccionar ante este suceso que ocasionalmente ha venido: Jerónimo intrépido como era, se ve impotente para herir en lo más mínimo la paciencia de Agustín, que día a día se está ganando su simpatía, simplemente por esto. En cartas posteriores le pide excusa si en algo le ha molestado y manda intermediarios para convencerlo ${ }^{25}$.

Por fin, Jerónimo después de haberse cerciorado de todo to sucedido, se decide a responder a sus cuestiones. Le da la contestación punto por punto, lo del título del libro, lo de la cuestión antioquena, lo de las traducciones y demás ${ }^{26}$. Desde este momento,

19. AUG. Epist. 67,1 PL 33,236 .

20. Aug. Epist. 67,1 PL 33,237.

21. Aug. Epist. 67,8 PL 33,237 .

22. HIER. Epist. 102,1 PL 22,830.

23. HIER. Epist. 102,2 PL 22,830.

24. HIER. Eprist. 105, 3-4 PL 22, 835-836.

25. AUG. Epist. 74 PL 33,250 .

26. HIER. Epist. 112,3 PL 22,917. 
Agustín seguirá tratándose con Jerónimo con más confidencia y llegará hasta preguntarle sobre temas candentes en este tiempo, especialmente en la controversia pelagiana, aunque reciba muy pocas luces ${ }^{27}$. A su vez, Jerónimo se va convenciendo de lo que significa para él Agustín y en una de sus últimas cartas no sabrá cómo alabar a este paladín de la fe en la herejía pelagiana; así, al final de una de sus cartas canta un himno de alabanza y de orgullo personal por haber encontrado a un tal amigo ${ }^{28}$.

De esta manera hemos llegado al culmen de las relaciones tan dispares entre dos doctores de la Iglesia. El león, que en años anteriores rugía en el desierto, se ha convertido en oveja mansa y zalamera. Jerónimo llegó a comprender que allí, bajo aquellas cartas que a primera vista parecían invectivas, encuentra a Agustín lleno de simpatía y amor auténtico.

Pero después de este breve recorrido que hemos hecho en el epistolario, muy poco hemos encontrado en lo que a nuestro estudio respecta. Solamente alguna insinuación al tema de Joviniano en la polémica con Jerónimo y tan sólo por parte de Agustín, el cual cita el libro de Jerónimo expresamente ${ }^{29}$. Este hecho de haber citado el libro de Jerónimo, nos lleva de la mano para hacer ciertas conclusiones de la significación del libro de Agustín en relación con el de Jerónimo. Por lo tanto el libro de Jerónimo no era desconocido para Agustín como hemos podido ver.

\section{B. JOVINIANO VISTO POR LOS DOS ESCRITORES.}

A medida que seguimos la trayectoria de la relación AgustínJerónimo, de nuevo nos podemos proponer otra pregunta: ¿Pode-

27. AUG. Epist. 166 PL 33, 720-733.

28. HIER. Epist. 141 PL 22,1179: “...Scit, quid dicam, prudentia tua. Macte virtute, in orbe celebraris. Catholici te conditorem antiquae rursum fidei venerantur atque suscipiunt et - quod signum maioris gloriae est - omnes haeretici detestantur, et me pari prosequuntur odio, ut, quosi gladiis nequunt, voto interficiant. Incolumen et mei memorem te Christi Domini clementia tueatur, domine venerande et beatissime papa".

29. Aug. Epist. 166, 3,6: "Sed quia tenemus de hac re sententiam tuam concinantem catholicae fundatissimae fidei, qua et Joviniani vaniloquia redarguens, adhibuisti testimonium ex libro Job. 'Nemo mundus in conspectu tuo, nec infans cuius est diei unius vita super terram' (Job XV, 4 sec. LXX), deinde adiunxisti, 'Tenemurque rel in similitudinem praevaricationis Adae' (HIER. Lib 2 adv. Jovinianum).

Epist. 166, 7,21: "Cui delicto obnoxios parvulos nosci, et omnis credit Ecclesia, et ipse iam contra Jovinianum disputans et expones Jonam prophetam, sicut paulo ante commemoravi, fide veracissima definisti". PL 33, 730 . 
mos afirmar, basados en textos internos de las diversas obras de los dos escritores, que los libros "De bono coniugali" y "Adversus Jovinianum", fueran directamente dirigidos a refutar la doctrina de Joviniano? $Y$ la respuesta la vamos a recibir de ellos mismos entresacando de sus diferentes obras, lo que sobre el argumento que nos preocupa en esta parte digan.

\section{La persona de Joviniano y su obra en S. Jerónimo.}

El acceso a la persona de Joviniano y a su obra nos es dado con suma claridad por S. Jerónimo nada más abrir sus libros. Nos limitaremos a los elementos esenciales. Jerónimo al principio del "Adversus Jovinianum" dirá que llegaron a sus manos ciertos "Comentariolos" de Roma a los cuales le piden que responda ${ }^{30}$. No es gran cosa lo que encontramos en Jerónimo sobre dicho personaje, pero sí lo suficiente para llegar a una idea más o menos precisa sobre su vida y sus doctrinas. Nos dice que fue monje, usando una metáfora realista hasta el extremo ${ }^{31}$. Por lo demás ni nos dice de dónde era, ni cuándo vivió, ni dónde. Se divierte con una crítica mordaz en echarle epítetos y en buscar el origen y derivación de su nombre; apelando a los dioses profanos ${ }^{32}$, 10 califica sarcásticamente como el "Epicuro de los cristianos" ${ }^{33}$, añadiendo que fue un maestro que tuvo muchos adeptos en su doctrina especiaImente entre los monjes de los dos sexos ${ }^{34}$.

A cuatro sentencias resume toda su doctrina, de las cuales nos vamos a servir aquí para dar un esquema de la misma. Una primera proposición de Joviniano, la reduce Jerónimo a decir que todos aquellos que están bautizados en el nombre del Señor, tienen ·igual mérito ante Dios, bien sea que se hayan casado o bien que hayan abrazado la vida de célibes en el monasterio o fuera. Sobre esta proposición van a girar todos los problemas que surgirán después en la respuesta dada por Jerónimo a sus amigos de Roma.

Puesto el principio general de la igualdad de los bautizados

30.. Adversus Jovinianum, I. 1 PL 23,221: "Pauci admodum dies sunt quod sancti ex urbe Roma fratres cuiusdam mihi Joviniani commentariolos transmiserunt, rogantes, ut eorum ineptiis responderem..."

31. IV. I, 40 PL 23, 280: "Monachus Jovinianus canis revertens ad vomitum",

32. IV. II, 38 PL 23, 352: "Cave Joviniani nomen, quod de (Jove) idolo derivatum est",

33. Ib. I, 1 PL 23,221: "Epicurus Christianorum". 
ante Dios obrando de una misma manera, aunque sea diferente su estado de vida, sigue proponiendo una segunda tesis aflrmando que los bautizados por el hecho de estar bautizados de ninguna manera pueden caer en pecado.

En la tercera tesis demostrará que no existe diferencia alguna ante Dios en cuanto al mérito, bien sea que se ayune o que se coma con acción de gracias.

$\mathrm{Y}$ por fin, como una consecuencia lógica de los principios dados anteriormente, concluye con una cuarta proposición subrayando que todos aquellos que hayan observado la ley bautismal tenđrán la misma remuneración en el reino de los cielos ${ }^{35}$.

De una manera concisa y en su nitidez auténtica libre de toda otra interpretación, tenemos el cuerpo de la doctrina de Joviniano según el mismo S. Jerónimo nos la ha transmitido en su obra " $A d-$ versus Jovinianum". En otra de sus obras "Dialogus contra Pelagianos" dirá que esta doctrina fue condenada en Roma y en Africa, hablando sobre el bautismo en la controversia pelagiana ${ }^{36}$. Doctrina por lo tanto condenada la de Joviniano por la Sede Apostólica $^{37}$.

2. La persona de Joviniano y su obra en S. Agustin.

Ya en líneas anteriores hemos hecho una insinuación sobre el beas".

34. Ib. II, 36 PL 23,349: "Ne glorieris quod multos discipulos ha-

35. Adversus Jovinianum, I, 3 PL 23,224: "Dicit, virgines, viduas, et maritatas quae semel in Christo lotae sunt, si non discrepent caeteris operibus, eiusdem esse meriti.

Nititur approbare eos, qui plena fide in baptismate renati sunt, a diabolo non posse subverti.

Tertium proponit, inter abstinentiam ciborum et cum gratiarum actione xierceptionem eorum, nullam esse distantiam.

Quartum quod et extremum, esse omnium qui suum baptisma servaverint, unam in regno coelorum remunerationem.

Hemos querido copiar integramente el texto del Santo con el fin de no desvirtuar las tesis de Joviniano y como una llamada a la interpretación protestante dada por G. GRUETZMACHER en su obra Hieronymus. Eine biographische Studie zur alten Kirchengeschichte. (Berlin 1901) II, 151.

36. Dialogus contra Pelagianos. III, 1 PL 23, 595: “Non erubescis explosam atque damnatam Joviniani sententiam sequi? Et ille enim his testimoniis tuisque nititur argumentis; immo tu illius invecta sectaris, in Oriente docere desiderans, quae olim Romae et dudum in Africa condemnata sunt".

37. MANSI, III , 663. 
conocimiento que tenía $\mathbf{S}$. Agustín del libro de $\mathbf{S}$. Jerónimo. El hereje Joviniano por consiguiente no era desconocido para Agustín. Ni su vida, ni sus doctrinas habian pasado desapercibidas para el obispo de Hipona, consciente de la misión que tenía que desarrollar en su diócesis de pastor y maestro. Para no aumentar el número de citaciones en las obras del Santo, nos ha parecido oportuno limitarnos a dos pasajes de distintas obras en los cuales nos lo presenta con colores de historiador de las herejías que por aquél entonces surgian o habian ya hecho su efecto en distintas partes de la Iglesia.

En el catálogo de herejías que viene examinando tiene su correspondiente lugar la herejía de los jovinianistas, no desconocidos para él, ya que confiesa abiertamente que los conocía de antemano. Siendo joven, había echado ya sus raíces teniendo como fundador de la misma a un tal Joviniano monje. La doctrina era clara. Confesaba la igualdad de todos los pecados a la manera de los flósofos estoicos. $\mathrm{Y}$ tanto es así, que incluso llegaba a decir que todos los bautizados no podrían de ninguna manera ser presa de las tentaciones del demonio y por consiguiente ser reos de pecado, a la vez que de nada servía el ayuno en la vida personal. Se atrevió incluso a negar la virginidad de María y no admitía diferencia alguna entre el estado de perfecta castidad y el del matrimonio. Hasta tal extremo llegó la influencia de su predicación, que en la ciudad de Roma muchas de las consagradas al Señor nada más oír sus doctrinas se esposaban con toda tranquilidad de conciencia. Y éstas no eran de las más jóvenes solamente, sino también de las entradas en años. El, sin embargo, no se casó ni quería tener mujer, y esto lo hacía no porque fuera a tener más mérito en el reino de los cielos, sino simplemente por evitar las molestias que la vida conyugal lleva consigo. No obstante, al final la herejía se extinguió, a pesar de que dejara todavía ciertas huellas en el pensamiento y en la concepción de la vida espiritual especialmente monacal ${ }^{38}$.

38. De Haeresibus, 82 PL 42, 45-46: "Jovinianistas quoque apud istum reperi, quos iam. noveraĭ. A Joviniano monacho ista haeresis orta. est aetate nostra, cum adhuc iuvenes essemus. Hic omnia peccata, sicut stoici philosophi, paria esse dicebat, nec posse peccare hominem lavacro regenerationis accepto, nec aliquid xirddesse jejunia, vel a cibis aliquibus abstinentiam. Virginitatem Mariae destruebat, dicens eam pariendo fuisse corruptam. Virginitatem etiam sanctimonialium, et continentiam 
En el libro de las Retractationes, cuando llega el momento de pasar revista al "De Bono coniugali" nos da en unas breves líneas ciertos principios de la doctrina de Joviniano, citando alguno de los argumentos usados por él para refutarlos. E implícitamente hace alusión al libro de Jerónimo, quizás llevado de cierta prudencia hacia el Santo que lo conocía suficientemente a través de todas sus cartas ${ }^{39}$.

De estos textos que hemos aducido, podemos colegir que Joviniano para Agustín no era un hereje desconocido, sino que trató como en todas sus polémicas, antes de comenzar la discusión, conocer perfectamente toda la doctrina del adversario. Roma e Hipona ya en aquel entonces podemos decir que no estaban tan distantes y las noticias corrían de un lugar a otro con cierta rapidez. Lo que sucedía en Roma no tardaba en llegar a conocimiento de los círculos africanos; además, muy posiblemente Agustín tuviera testigos de experiencia al igual que practicantes de las ideas de Joviniano en su diócesis. Por otra parte, el libro de Jerónimo, como hemos dicho, le era conocido ${ }^{40}$. Sólo quedaba el poner manos a la obra y tomar la pluma. La doctrina del hereje había que combatirla y extirpar aquel confusionismo que la contestación de Jerónimo a la doctrina de Joviniano había causado. A esto va a ir dirigida su obra como ya nos lo dejó indicado y a aclarar las ideas dadas por Jerónimo según las cartas de Pammaquio y Domnión ".

sexus virilis in sanctis eligentibus caelibem vitam, coniugiorum castorium atque fidelium meritis adaequabat:ita ut quaedam virgines sacrae provectae iam aetatis in urbe Roma, ubi haec dacebat eo audito nupsisse dicaniur. Non sane ipse vel habebat vel habere volebat uxorem: quod non propter aliquod axud Deum maius meritum in regno vitae perpetuae profuturum, sed propter praesentem prodesse necessitatem, hoc est, ne homo coniugales patiatur molestias, disxutabat. Cito tamen ista haeresis oppressa et exstincta est, nec usque ad deceptionem aliquorum sacerdotum potuit pervenire".

39. Retrac. 22, I PL 32,639: "Joviniani haeresis, sacrarum viginum meritum, edquando pudicitiae, tantum valuit in urbe Roma, ut nonnullas etiam sanctimoniales, de quarum rudicitia suspicio nulla praecesserat, deiecisse in nuptias diceretur, hac maximo argumento cum eas urgeret dicens:'Tu ergo melior quam Sara, melior quam Susanna, sive Anna?...' Sed etiam occulte venenis repentibus, facultate, quam donabat Dominus, occurrendum fuit: maxime quoniam iactabatur Joviniani responderi non potuisse cum laude, sed cum vituperatione nuptiarum. Propter hoc librum edidi, cuius inscriptio est, De Bono coniugali".

4.0. Aug Epist. 166, 3, 6 PL 33, 723; ib. 7, 21 PL 33, 730. 516.

41. HIER. Epist. 48 PL $22,493-511 ; 49$ PL 22, 511-512; 50 PL 22, 512- 
C. PARANGON ESCRITURISTICO Y DOCTRINAL.

\section{ADVERSUS IOVINIANUM}

\section{ANTIGUO TESTAMENTO}

Gn. 1,18: "Crescite et multiplicamini, et replete terram". I, 16 PL 23, 246.
Id.: "Crescite et multiplicamini, et implete terram".

2,2 PL 40, 373.

\section{NUEVO}

I Cor. 7,4: "Uxor proprii cor poris non habet potestatem, sed vir. Similiter et vir sui corporis non habet potestatem, sed uxor".

I,7 PL 23, 230.

$I$ Cor. 7,5: "Nolite fraudare invicem, nisi forte ex consensu ad tempus, ut vacetis orationi".

I,7 PL 23, 230.

$I$ Cor. 7,7: "Volo autem omnes homines esse sicut meipsum".

I,8 PL 23, 231.

$I$ Cor. 7,8-9: "Dico autem innuptis et viduis: bonum est, si sic permanserint, ut ego. Si autem non se continent, nubant. Melius enim est nubere quam uri".

I,9 PL 23, 232.

$I$ Cor. 7,28: "Si autem acceperis uxorem, non peccasti. Et si nupserit virgo, non peccavit".

I,13 PL 23, 240.

I Cor. 7,34: "Mulier innupta

\section{TESTAMENTO}

Id.: "Uxor (mulier) non habet potestatem corporis sui, sed vir; similiter et vir non habet potestatem corporis sui, sed mulier".

6,6 PL 40, 377; 4,4 PL 40, 376.

Id.: "(No lo cita expresamente, aunque hace exégesis del mismo).

10,11 PL 40, 381.

Id.: "Vellem omnes esse sicut me ipsum".

10,10 PL 40, 381.

Id.: "Si se non continent, nubant". "Quod si se non continent, nubant. Melius est enim nubere quam uri".

10,10 PL 40, 381.

17,19 PL 40, 386.

Id.: "Si acceperis uxorem, non peccasti; et si nupserit virgo, non peccat".

10,11 PL 40, 381.

11,12 PL 40, 382.

Id.: "Quae innupta est, co- 
et virgo cogitat quae sunt Domini ut sit sancta corpore et spiritu".

I,13 PL 23, 241. gitat ea quae sunt Domini; ut sit sancta et corpore et spiritu".

11,13 PL 40, 382.

\section{CONCLUSIONES GENERALES}

\section{Filológicas:}

Una cuestión de fondo quedạ patente al hacer la comparación de textos que ha precedido: la diversidad del texto de la Escritura usado por uno y otro, condicionada por el tiempo en que ambos escriben sus libros, al igual que por circunstancias especiales en la recepción de traducciones de la Biblia.

Conocemos la posición de Jerónimo en torno a la Palabra de Dios; gustaba de tenerla en su pureza y nitidez auténtica. Para esto nada mejor que ir directamente al texto original, e incluso decidirse a hacer por si mismo la traducción. Agustín, recio pensador del misterio revelado, no dejando a un lado la traducción más o menos fiel de la palabra divina, recibe el texto de la "Vetus lati$n a$ " común en su tiempo, guiado, sin duda, por razones pastorales, tema al cual van dirigidos todos sus escritos. Por esto nada es de extrañar la diversidad que hallamos en uno y otro.

En cuanto a la frecuencia de las citaciones, basta abrir las obras y nos percataremos al instante de la abundancia de textos en Jerónimo, llegando al extremo de abusar de ellos y trayéndolos a colación cuando deberían quedar en silencio. Agustín, por el contrario, es más parco y mesurado cuando llega el momento de probar sus asertos con textos de la Sagrada Escritura.

\section{Exegéticas y doctrinales:}

En el análisis de los diversos capitulos estudiados por uno y otro en sus obras, especialmente en lo que a la doctrina del matrimonio se refiere, tema crítico y central en ambas obras, topamos con el hecho ya insinuado, de que todas sus afirmaciones y argumentos están basados en la Escritura. De aquí que nada mejor que considerar de una manera global estos dos aspectos. Quedará clara la diversa interpretación en uno y otro de los textos escriturísticos en la fundamentación de sus tesis. 
A uno de los primeros interrogantes al cual nos urge dar contestación en el examen de ambas obras, es al de la bondad del matrimonio.

a) ¿El matrimonio es un bien?

La respuesta no podemos por menos de darla, situados según el pensamiento desarrollado en las dos obras y guiados por sus afirmaciones si no queremos adulterar el texto. Para Agustín no hay problema en la contestación a tal interrogante. Podemos considerar la bondad del matrimonio en sí, o en comparación con otros bienes: aquí en concreto será con la virginidad. Distinción ésta, que encontramos precisada especialmente en Agustín, dado que Jerónimo, como veremos, no podrá considerar el matrimonio y su bondad o menos sino en comparación con la virginidad y viudez. El Africano insistirá concienzudamente en la afirmación de la bondad del mismo considerado en sí, mitigando ciertos asertos tajantes e infundados de Jerónimo.

En realidad, cuando nos ponemos a examinar el pensamiento jerominiano sobre el bien del matrimonio, tenemos que dejar ya desde un principio clara la concepción original de "bien" expuesta por él mismo. "Bonum -dirá- est illud naturaliter, quod comparationem non habet mali, quod praelatione alterius non obumbratur" ${ }^{42}$. Ahora bien, según esto, dado que al matrimonio se le compara con la fornicación, luego no es un bien. Concepción verdaderamente original, de no fácil inteligencia, pero que, por otra parte, se nos presenta lógico en su pensamiento, de ordinario voluble e inseguro por infundado.

Con esta premisa, podemos entrar en el examen de textos de uno y otro. Una comparación de los mismos, dejará patente de una manera sistemática la función desarrollada por la obra de Agustín en relación con la de Jerónimo.

\section{ADVERSUS JOVINIANUM}

"Revertamur ad caput testimonii: Bonum est, inquit, homini mulierem non tangere.

\section{DE BONO CONIUGALI}

"Illud nunc dicimus, secundum istam conditionem, nascendi et moriendi, quam novi-

42. Adv. Jovinianum I, 7 PL 23, 229. 
Si bonum est mulierem non tangere, malum est ergo tangere: nihil enim bono contrarium est nisi malum. Si autem malum est, et ignoscitur, ideo conceditur, ne malo quid deterius fiat. Quale illud bonum est, quod conditione deterioris conceditur? ${ }^{43}$.

"Si per se nuptiae sunt bonae, noli illas incendio comparare: sed dic simpliciter, bonum est nubere. Suspecta est mihi bonitas eius rei, quam magnitudo alterius mali malum esse cogit inferius. Ego autem non levius malum sed simplex bonum per se volo" ${ }^{45}$.

Non repudio nuptias, habes et sinistrum oculum, quem tibi dedit propter imbecillitatem eorum, qui recta videre non possunt" ${ }^{66}$. mus, et in qua creati sumus, aliquid bonum esse coniugium masculi et feminae: cuius confederationem ita divina Scriptura commendat, ut nec dimissae a viro nubere liceat alteri, quandiu vir eius vivit; nec dimisso ab uxore liceat alteram ducere, nisi mortua fuerit quae recessit. Bonum ergo coniugii, quod etiam Dominus in Evangelio confirmavit, non solum quia prohibuit dimitere uxorem, nisi ex causa fornicationis, sed etiam, quia venit invitatus ad nuptias, cur sit bonum merito quaeretur" 44 .

La inseguridad e incertidumbre en la postura tomada por Jerónimo cuando habla del tema del matrimonio al dar contestación a las tesis de Joviniano, nos habla bien a las claras de la volubilidad de su pensamiento, al menos, objetivamente consideradas sus afirmaciones. Como hemos podido notar en la relación de textos que ha precedido, encontramos algunos en que abiertamente parece negar la bondad del matrimonio, otros en los cuales parece afirmarla, siempre con cierto temor y otros en que decididamente dice

43. Adv. Jovinianum I, 7 PL 23, 229; I, 7 PL 23, 230; I, 7 PL 23, 231; I, 9 PL 23, 233; I, 13 PL 23, 243; I, 14 PL 23, 244.

44. De Bono Coniugali, 3, 3 PL 40 375. La misma idea la desarrolla en: Ib. 16, 18 PL 40, 385; 19, 22 PL 40, 389; 20, 23 PL 40, 389; 20, 24 PL 40,$389 ; 17,19 \mathrm{PL} 40,386 ; 8,8$ PL $40,379$.

45. Adv. Jovinianum I, 37 PL 23, 274; I, 37 PL 23, 275.

4.6. Ib. I, 30 PL 23, 265; I, 3 PL 23, 223; Epist. 48 PL 22, 493-511. 
que él de ninguna manera condena las nupcias, pero que prefiere la virginidad al matrimonio ${ }^{47}$.

Las conclusiones que podemos extraer de este conglomerado de afirmaciones, a primera vista contradictorias, son fáciles y a la vez difíciles. Jerónimo nunca considera el matrimonio y su bondad en sí, sino siempre en comparación o con la virginidad o con la continencia, o con la viudez ${ }^{48}$; por otra parte, dada la inferioridad en que coloca al matrimonio en relación con la virginidad ${ }^{49}$, nada extraña la confusión causada por su obra en Roma ${ }^{50}$.

Agustín, equilibrista en el trapecio doctrinal de la Iglesia, pondrá en su punto auténtico la bondad del matrimonio. Dando un lugar de preeminencia a la Sagrada Escritura por su autoridad, insiste en la indisolubilidad del matrimonio y en la fidelidad conyugal, temas tratados por Jerónimo con cierta lógica. Cristo en el Evangelio muestra bien a las claras la bondad del matrimonio y Agustín, en confirmación de esta verdad, nos pone el caso típico ya en toda la patrística, de la asistencia a las bodas de Caná del mismo Cristo. Razones éstas a las que añade la sociedad natural en diverso sexo entre el marido y la mujer y la ordenación de la concupiscencia hacia un fin recto y noble como es el de lạ procreación. La bondad del matrimonio vendrá incluso manifestada por la práctica del mismo tanto en el Antiguo Testamento con los Patriarcas como en el Nuevo bajo la doctrina del mensaje evangélico. Por lo tanto, no hay lugar a duda de ninguna clase y el cristiano caminará siempre con paso firme a la hora de la decisión.

\section{b) Bienes del matrimonio:}

Ceñidos al argumento esencial de dichas obras, seguiremos haciendo el examen por los diversos apartados en la doctrina del matrimonio más sobresalientes, en las cuales las afirmaciones menos precisadas por Jerónimo, vienen puestas en orden por Agustín.

47. Adv. Jovinianum, I, 33 PL 23, 268:".. Sed ita nuptias recipimus, ut virqinitatem, quae de nuxtiis nascitur, praeferamus, Cfr. I, $3 \mathrm{PL} 23$, 223 ; Enist. 48, 5 PL 22, 4.96.

48. Ib. I, 32 PL 23, 266; I, 33 PL 23, 267; I, 3 PL 23, 223; I, 37 PL 23, 276; Epist. 49, 2 PL 22, 511.

49. Ib. I, 29 PL 23, 262: "Simulque nos commonet ne legem Evanlio praeferamus; ne puritatem virginitatis, nuptiis putemus aequandam..." Cfr. también I, 40 PL 23, 281-282.

50. Epist. 48 PL 22, 493-511; Epist. 49 PL 22, 511-512; Epist. 50 PL 22, 512-516. 
Jerónimo es el hombre que lucha siempre con la Bilia en la manoy en la pluma, si se nos permite la expresión. El argumento "ad hominem" tiene puesto de preferencia en sus obras polémicas. Se dirigirá continuamente a la Escritura, en concreto aquí al Apóstol Pablo y al Evangelio, usando los mismos textos que el adversario tomaría para defenderse ${ }^{51}$. Entresacaremos algún texto que hallamos en su asistemático método de exposición.

\section{ADVERSUS JOVINIANUM}

"Uxor proprii corporis non habet potestatem, sed vir. Similiter et vir sui corporis non habet potestatem, sed uxor. Omnis haec quaestio de his qui in matrimonio sunt, an eis liceat uxores dimittere, quod et Dominus in Evangelio prohibuit. Unde et Apostolus, Bonum est homini, ait, uxorem non tangere. Sed quia qui semel duxit uxorem, nisi ex consensu, se non valet abstinere, nec dare repudium non peccanti, reddat coniugi debitum: sponte quippe se alligavit, ut red-lere cogeretur" 52

"Si abstinemus nos a coitu, honorem tribuimus uxoribus: si non abstinemus, perspicuum est honorem contrariam esse contumeliam" ${ }^{54}$.

"Si virginitatem Dominus imperasset, videbatur condem-

\section{DE BONO CONIUGALI}

"Generationis itaque causa fieri nuptias, Apostolus jta testis est: "Volo, inquit, iuniores nubere. Et quasi ei diceretur, Ut quid? continuo subiecit, filios procreare, matres familias esse. Ad fidem autem cartitatis illud pertinet. Uxor non habet potestatem corporis sui, sed mulier. Ad sacramenti sanctitatem illud, Uxorem a viro non discedere, quod si discesserit, manere innuptam, aut viro suo reconciliari: et vir uxorem non dimittat. Haec omnia bona sunt, propter quae nuptiae bonae sunt, proles, fides, sacramentum" ${ }^{53}$.

51. Adv. Jovinianum I, 6 PL 23, 228; HrER. Epist. 48, 2 PL 22, 494. 239 .

52. Adv. Jovinianum I, 7 PL 23, 230; I, 12 PL 23, 238; I, 27 PL 23,

53. De Bono Coniugali 24, $32 \mathrm{PL} 40,394$.

54. Adv. Jovinianum I, 7 PL 23, 230; I, 7 PL 23, 231. 
nare nuptias, et hominum auferre seminarium, unde et ipsa virginitas nascitur. Si praecidisset radicem, quomodo fruges quaereret"? ${ }^{55}$.

Como hemos podido observar en la exégesis hecha por Jerónimo a 1 Cor. 7,4 insiste con cierta lógica en la auténtica interpretación del texto sobre la fidelidad conyugal y la obligación que tienen los esposos de darse el débito conyugal y a la vez, la prohibición de abstenerse del mismo por razones de continencia perpetua sin el consentimiento del otro. Igualmente hace notar Jerónimo la necesidad de la indisolubilidad matrimonial poniendo como base las enseñanzas del Evangelio. No obstante, siempre podemos encontrar afirmaciones en cierto sentido contradictorias o, al menos, no muy consecuentes con las afirmaciones precedentes, especialmente por las dificultades anejas al acto conyugal. Pero, a pesar de todas estas afirmaciones dadas, dejado llevar sin duda de la fuerza de la polémica, creemos que el pensamiento de Jerónimo a este respecto es de conformidad con Pablo en conceder el débito conyugal legitimamente ${ }^{56}$.

Solamente ve justificada la bondad del matrimonio en cuanto a la procreación, en cuanto que es el principio de donde pueden nacer las vírgenes; en realidad, dice él, no existirían éstas si no se diese aquél, por otra parte las nupcias no están condenadas al situar la virginidad no como precepto sino como consejo. El Nuevo Testamento, dice en otro texto, en concreto a la exégesis que hace a Gn 1, 28, es tiempo de abstenerse del matrimonio, dado que el Antiguo fue el tiempo de la siembra y crecimiento ${ }^{57}$. Agustín hará exégesis al mismo texto del Génesis al principio de su libro, pero toma otros derroteros sobre la manera cómo se daría el matrimonio si no hubiese existido el pecado, dejando a un lado la idea un poco pesimista jerominiana ${ }^{58}$.

Ante todo este conglomerado de asertos dados por Jerónimo, expuestos sin duda a falsas interpretaciones por parte del pueblo

55. Ib. I, 12 PL 23, 237: I, 3 PL 23, 223

56. Adv.. Jovinianum I, 16: "Postquam nuptis concesserat usum coniugii, etc..."

57. Ib. I, 16 PL 23, 246

58. De Bono Coniugali 2, 2 PL 40, 374-375. 
y del clero, la doctrina de Agustin expuesta en su libro se nos presenta clara y precisa. Agustín ve la dificultad, trata de poner remedio y con su método sistemático, cimentando sus afirmaciones en la Escritura, camina con pie firme al momento de proponer sus tesis.

Al final de su obra, en una sintesis maravillosa y clara, expone los bienes del matrimonio. Un primer bien del matrimonio lo tenemos en la procreación, "bonum prolis" ${ }^{59}$; en el "bonum fidei" o la fidelidad conyugal se resume el segundo ${ }^{60}$. Insiste Agustín en este punto sobre la obligación que tienen los esposos de darse el débito conyugal y abstenerse del mismo cuando otras causas superiores 10 exijan. Finalmente, un tercer bien "bonum sacramenti" que implica la indisolubilidad y la unidad del matrimonio ${ }^{61}$. Ya no hay lugar a duda en la doctrina de los bienes del matrimonio y la tesis de Joviniano queda solucionada, a la vez que el confusionismo de Jerónimo lo deja superado.

\section{c) La oración Matrimonial.}

La obra de Agustín centrada primordialmente sobre los puntos base de la teología matrimonial, no podía por menos que detenerse en el examen detallado de textos escriturísticos, como hemos podido venir observando en líneas anteriores. Jerónimo, temperamento incontrolado en discusión con el adversario, sigue haciendo afirmaciones rayantes en la herejía acerca de la doctrina que defiende contra Joviniano. $\mathrm{Y}$ es en dos temas cumbres en el cristianismo, la oración y recepción del sacramento eucarístico, donde deja malograda toda la temática en torno al matrimonio. En sus asertos objetivamente considerados podemos ver sin más la influencia dualística en el fondo de la interpretación que hace del texto en 1 Cor 7,5 .

59. Ib. 9,9 PL 40,$380 ; 10,11$ PL 40,$381 ; 11,12$ PL 40,$382 ; 17,19$ PL 40,386 .

60. Ib. 4, 4 PL 40, 376; 5, 5 PL 40, 377; 6, 6 PL 40, 377.

61. De Bono Coniugali 7,6 PL 40,$388 ; 13,15$ PL $4.0 .384-385 ; 15,17$ PL 40, 385; 17, 20 PL 40, 787; 18, 21 PL 40, 787. 


\section{ADVERSUS JOVINIANUM}

"Nolite fraudare invicem.nisi forte ex consensu ad tempus, ut vacetis orationi. Oro te, quale illud bonum est, quod orare prohibet? quod corpus Christi accipere non permittit? Quandiu impleo officium mariti non imple continentis. Iubet idem apostolus in alio loco ut semper oremus (I Thes. V). Si semper orandum est, nunquam ergo coniugio serviendum, quoniam quotieseumque uxori debitum reddo, orare non possum. Petrus apostolus experimentum habens coniugalium vinculorum, vide quomodo informet Ecclesiam, quid doceat christianos: similiter viri cohabitantes iuxta scientiam, quasi infirmiori vasculo mulieri tribuentes honorem, et sicut cohaeredes multiplicis gratiae, ut non impediantur orationes vestrae (I Petr. III, 7). Ecce eodem sensu, quia eodem et spiritu, impediri dicit orationes officio coniugali" "s.
DE BONO CONIUGALI

"Nec quod purificari lex hominem et post coniugalem concubitum iubet, peccatum esse declarat; si non est ille qui secundum veniam conceditur, qui etiam nimius impedit orationes" ${ }^{62}$.

"Nnn itaque nuptias secundum veniam concedit Apostolus: nam quis ambigat absurdissime dici non eos peccasse quibus venia datur? Sed illum concubitum secundum veniam concedit Apostolus, qui fit per incontinentiam, non sola causa procreandi, et aliquando nulla causa procreandi; quem nuptiae non fieri cogunt, sed ignosci impetrant: si tamen non ita sit nimius; ut impediat quae seposita esse debent tempora orandi, nec inmutetur in eum usum qui est contra naturam, de quo Apostolus tacere non potuit cum de corruptelis nimiis inmundorum et impiorum hominum loqueretur" ${ }^{64}$.

Nos bastan estas breves citaciones para comprender el pensamiento de cada uno de los autores. Ya desde un principio conviene hacer una distinción, que viene exigida por sus mismas afirmaciones. Jerónimo habla sin más del matrimonio en si y del acto con-

62. Ib. 20,23 PL 40,389 .

63. Adv. Jovinianum I, 7 PL 23, 230; I, 12 PL 23, 238; I, 34 PL 23, 269 ; HrER. Epist. 48, 15 PL 22, 506.

64. De Bono Coniugali 10, 11PL 40, 382. 
yugal que se realice dentro del matrimonio y según el fin al cual debe ir dirigido, es decir a la procreación. Ya en este mismo acto encuentra un desorden no muy concorde con el deber de todo cristiano de orar y también de recibir la Sagrada Eucaristía. Los deberes conyugales, en resumen, no permiten orar $y$, por lo tanto, no confía Jerónimo en la bondad de tal bien. Si está mandado que siempre hay que orar al Padre, como lo prueba Jerónimo con textos del Apóstol Pablo, luego nunca será lícito el dar el débito conyugal cuando te lo pidan, sería causa de pecado, o al menos de tal imperfección que no permitiría acercarse a la oración ni al banquete eucarístico.

Estamos dando el pensamiento del texto citado. Las contradicciones en Jerónimo las encontramos al paso. Sin duda que vienen condicionadas por su método polémico en este caso y casi siempre escrito sin pensar en las conclusiones que los demás pueden sacar de sus afirmaciones.

Como siempre, a resolver estas contradicciones y a poner el equilibrio requerido en tal doctrina viene al instante la obra de Agustín. Comienza el autor dejando a un lado ya de una vez para siempre la total ausencia de pecado ni de falta alguna en las relaciones matrimoniales. A la frase del Apóstol que Jerónimo cita en confirmación de sus asertos, Agustín le da un sentido distinto de impedimento dado por Jerónimo y por consiguiente de falta más o menos grave. Agustín admite la imperfección en el acto matrimonial realizado como él dice "proter incontinentiam", no por el fin primordial de la procreación ${ }^{65}$. Este será el punto débil hacia el cual todos los autores tienden su mirada cuando quieren juzgar el pensamiento de Agustín a este respecto. En este caso, sin duda, Agustín hace observar que puede ser causa de cierta relajación y ausencia en la oración de las relaciones con Dios, especialmente cuando pasa el límite de lo justo (vid. nota 64). Pero de ninguna manera serán causa de esta deficiencia en la oración las relaciones matrimoniales dentro del mismo por razones de procreación, las cuales están ausentes completamente de culpa cuando se realizan ${ }^{66}$.

65. De Bono Coniugali 5, 6 PL 40, 377: "Coniugalis enim concubitus generandi causa, non habet culpam: concupiscentiae vero satiandae, sed tamen cum coniuge, propter thori fidem, venialem habet culpam: adulterium vero sive fornicatio laetalem habet culpam". Cfr. 10, 11 PL 40, 382.

66. Ib. 5, 5 PL 40,$377 ; 6,6$ PL $40,378$. 
Concuerdan plenamente las afirmaciones agustinianas con el pensamiento general del mismo sobre la oración llamada "vital" de de una portada transcendental para la vida de todo cristiano. $Y$ el cristiano auténtico es aquél que dentro o fuera del matrimonio cumple con su deber totalmente entregado a la obra de su propia santificación.

\section{d) ¿Matrimonio "secundum indulgentiam"?}

Para no detenernos más en el examen de textos de ambas obras, vamos a poner punto final con este apartado, sin duda deficiente también en la obra de Jerónimo y arriesgado en sus tesis, a la vez que abierto a una mala inteligencia en la polémica contra Joviniano. Como hemos podido venir observando a través de todo este trabajo y en los puntos a que hemos hecho alusión con el fin de hacer resaltar más la labor realizada por la obra de Agustín, Jerónimo no se separa de la Escritura y da la interpretación que a primera vista se le presenta, sin detenerse en más consideraciones.

A la respuesta dada a la pregunta inicial, Jerónimo no encuentra dificultad alguna. La frase del Apóstol Pablo en 1 Cor 7,6 "Hoc autem dico secundum indulgentiam, non secundum imperium", según Jerónimo claramente muestra, que el matrimonio lo aconseja el Apóstol "secundum indulgentiam" y no "secundum imperium".

\section{ADVERSUS JOVINIANUM}

"Verum ne quis putet ex eo quod sequitur: "Ut vacetis orationi, et iterum revertimini ad ipsum, Apostolus hoc velle, et non propter maiorem ruinam concedere, statim infert: Ne tentet vos Satanas propter incontinentiam vestram. Pulchra nimirum indulgentia, et iterum ad ipsum. Quod erubescit suo vocare nomine, quod tentationi praefert

\section{DE BONO CONIUGALI}

"Iam in ipsa quoque inmo-
deratione ixactione debiti car-
nalis, quam eis non secundum
imperium praecipit, sed secun-
dum veniam concedit Aposto-
lus, ut etiam praeter causam
procreandi sibi misceantur;
etsi eos pravi mores ad talem
concubitum impellunt, nup-
tiae tamen ab adulterio seu
fornicatione defendunt. Neque
enim illud propter nuptias ad-


Satanae, quod causam habet incontinentiam, laboramus quasi obscurum disserere, cum expossuerit ipse quod scripsit. Hoc autem, inquit, dico iuxta indulgentiam, non iuxta imperium. Et mussitamus adhuc nuptias non vocare indulgentiam, sed praeceptum, quasi non eo modo et secunda et tertia matrimonia concedantur, quasi non et fornicatoribus per poenitentiam fores aperiantur Ecclesiae, quodque his est maius, et incestis?" ${ }^{68}$. mittitur, sed propter nuptias ignoscitur" ${ }^{67}$.

"Exigendi autem debiti ab alterutro sexu inmoderatior progressio, propter illa quae supra dixi, coniugibus secundum veniam conceditur" ${ }^{69}$

Por lo tanto según el sentir de Jerónimo, Pablo como conclusión de lo dicho anteriormente, dadas las dificultades que supone para la oración el matrimonio, cierra su pensamiento con esa frase que es broche de oro para la concepción del matrimonio "secundum veniam".

Los textos de Agustín en la crítica que hace a la frase del Apóstol son claros y además nos parecen directamente dirigidos a superar, aclarar y completar la exégesis dada por Jerónimo. Expresamente, comenta Agustín, que las nupcias no las concede $\mathbf{S}$. Pablo "secundum veniam", sino que lo que concede "secundum veniam" es la unión conyugal que se realiza por incontinencia ciertamente y no sólo por razón de la procreación de los hijos y, a veces, hasta quedará excluida ésta. Sin embargo, téngase en cuenta que no llegue a ser una acción que vaya contra la naturaleza y que se deje tiempo para la oración, dado que esto sería causa de cierta deflciencia en las relaciones con Dios. Y dado que esta concesión es del Apóstol Pablo para defender a los esposos del adulterio o de la fornicación, quedará justificado todo lo que de inmoderación y pecado pudiera existir en este acto. No obstante, hemos dicho arriba que Agustín este acto no lo deja sin cierta culpabilidad.

67. De Bono Coniugali 6, 6 PL 40,377

68. Adv. Jovinianum I \& PL 23, 231; I, $37 \mathrm{PL} \mathrm{23,} 276$.

69. De Bono Coniugali 11, 12 PL 40, 382; 7, 6 PL 40, 378. 
D. LA OBRA DE AGUSTIN FRENTE A LA DE JERONIMO.

Queriendo dar una conclusión lógica y precisa según el proceso de evolución en el pensamiento doctrinal tanto de la obra " $A d-$ versus Iovinianum" como en "De bono coniugali", proceso que ha venido condicionado por circunstancias históricas y de mentalidad đe una época, nos será de todo punto necesario el sintetizar en unas líneas todo este ambiente en que se escribieron.

De fuentes jerominianas sabemos la situación de Roma por los años 390 y siguientes. Joviniano, al frente de una revolución en el campo de la espiritualidad, hace pública su doctrina en Roma y alrededores. Los monasterios se sienten influenciados en primer término. La vida religiosa comienza a sentirse amenazada en sus fundamentos, y sus adeptos desconfían de la realidad de todo ese edificio doctrinal monástico.

Cartas de Roma con información detallada llegan a Palestina donde Jerónimo se encuentra con los suyos en su incipiente monacato proveniente de un proyecto particular. Insistentemente se le pide que dé solución a todo este conglomerado de afirmaciones propuestas por Joviniano sobre los principios de la vida cristiana y sus consecuencias, principalmente contra los diversos estados de perfección que comienzan a florecer en la Iglesia.

Ya hemos hecho alusión en líneas anteriores a la idea que se llegó a formar Jerónimo del presunto hereje. El Betlemita consciente de su responsabilidad en la misión de mantener el depósito de la Iglesia en su sentido real y pleno, comienza su redacción del "Adversus Iovinianum" con las características indicadas. El libro se difunde por toda Italia y demás países cristianos. Dadas las dificultades objetivas provenientes especialmente de su manera de expresarse, el libro en vez de aclarar todo este confusionismo causado por Joviniano, levanta más inquietud en todos los rincones de la cristiandad. Ahora, ya no sólo los monasterios, sino los simples cristianos se ven amenazados por las afirmaciones de Jerónimo, que queriendo exaltar el bien de la virginidad y de la vida continente deja en cuarentena toda la doctrina del matrimonio. Una inseguridad de doctrina en lo referente al concepto de matrimonio cristiano y virginidad se respira en todos los ambientes.

Las cartas dirigidas por Jerónimo a Pammaquio y Domnión 
nos dan fe de lo afirmado anteriormente. Estos dos amigos de Jerónimo se preocupan de recoger todos los manuscritos de Jerónimo y de nuevo escriben a Palestina contándole lo sucedido. El temperamento de Jerónimo no estaba para soportar tales interpretaciones a su libro y rápidamente contesta a las cartas. En esta misma contestación a sus cartas, Jerónimo, queriendo explicar de nuevo todas sus afirmaciones, deja todavía un subfondo de ciertas ideas sin solución verdadera y segura.

Durante todo este tiempo de polémica contra Joviniano, la Sede Apostólica se preocupa de condenarlo. Joviniano es declarado hereje, pero sigue persistiendo en sus ideas. Los monasterios comienzan a sentir un éxodo notable buscando mejor posición en la vida. Se sienten en cierto sentido engañados en todo lo referente a la espiritualidad monacal. Como siempre las ideas nuevas suelen tener aceptación en los que no han aceptado consciente y responsablemente un compromiso personal. Solamente se necesita alguien que sepa levantar la chispa, para que comience rápidamente el fuego.

En estas circunstancias de indiferencia y de inseguridad doctrinal, tanto en lo que a la doctrina del matrimonio se refiere, como a la virginidad, Agustín pone manos a la obra. El mismo, como hemos visto, lo dice expresamente. Su obra va dirigida contra Joviniano y, a la vez, a aclarar las afirmaciones de Jerónimo que no había podido responder con cierta aceptación y seguridad a las diflcultades propuestas por el hereje ${ }^{70}$. Joviniano era conocido por Agustín sin duda. Antes de comenzar a refutar su tesis, trata de conocerlas y de conocerle. Roma y Africa no se encuentran tan distantes. Lo que sucedía en Roma llegaba rápidamente al conocimiento de los africanos de Cartago y pueblos adyacentes. El, se encontraba en el centro de las dos partes afectadas tanto por parte de Joviniano, rechazando o rebajando la virginidad, como por parte de Jerónimo dejando en sus afirmaciones ciertas tesis infundadas sobre el matrimonio, al menos objetivamente. En Agustín se juntan el Padre de una familia religiosa con distintos monasterios y el Pastor de almas entregado completamente a su misión pastoral en medio de su pueblo. Por esto, nadie mejor que él podría dar una contestación con fundamento a todo este confusio-

70. Retract. I, 22 PL 32, 639. 
nismo de ideas en la doctrina de la Iglesia. De esta manera, ya tenemos solucionado el por qué del libro de Agustín en relación con el de Jerónimo. A través de este trabajo hemos podido ir viendo cómo ha ido realizando punto por punto la función primordial de aclaración y de puesta en orden de ciertas ideas de Jerónimo en lo que a la doctrina del matrimonio se refiere.

Quizás se pudiera pensar de la admisión de una cierta integración de doctrina por parte de Agustín en su obra con relación a la de Jerónimo. No la negamos en ciertas ideas base, recibidas de la tradición. Agustín siempre tuvo en gran estima esta fuente de la revelación cristiana. Hicimos alusión también a la actitud tomada frente a Jerónimo en la consulta que le hace sobre la Escritura y en la controversia pelagiana. Abierto a todos y dispuesto a aceptar todo lo que de bueno haya en los demás; la verdad es patrimonio común y Agustín estaba posesionado de esta realidad. Pero también la verdad ha de presentarse tal cual es, y librarla de toda confusión. Y aquí está la misión de la obra de Agustín, frente a la de Jerónimo, ambos luchadores y buscadores de la única Verdad.

Carlos Morán 